\title{
Presupuesto Participativo \\ Facultad Ciencia Política y Relaciones Internacionales - Universidad Nacional de Rosario
}

\section{Reseña presentada por Cintia Pinillos y Gisela Signorelli \\ Cintia Pinillos es Secretaria de Planificación y docente-investigadora de la Facultad de Ciencia Política y Relaciones Internacionales. \\ Gisela Signorelli es Secretaria Técnica de la edición 2011 del Presupuesto Participativo de la Facultad de Ciencia Política y Relaciones Internacionales y becaria del CONICET.}

A lo largo del segundo cuatrimestre de 2011 se implementó por primera vez el Presupuesto Participativo (PP) de la Facultad de Ciencia Política y Relaciones Internacionales, impulsado por la nueva gestión de gobierno. La incorporación de este dispositivo democrático en una institución pública de educación superior constituye una experiencia innovadora para la promoción de la participación de diversos actores en el proceso de toma de decisiones.

Las políticas participativas que implican la discusión sobre el destino de parte de los fondos públicos favorecen la información y la transparencia de las acciones, estableciendo ámbitos deliberativos en los que se involucran actores que habitualmente no participan de los espacios institucionales de decisión.

El objetivo principal que impulsó la incorporación del Presupuesto Participativo como herramienta de gestión democrática en nuestra Facultad, fue promover el involucramiento de los integrantes de los claustros docente, estudiantil y no docente en la definición sobre el destino del 10\% del presupuesto disponible.

De manera simultánea, a lo largo del proceso participativo se incentivó la inclusión de los miembros de la comunidad que quisieran sumarse a la iniciativa, el diálogo libre, informado y respetuoso entre los participantes, la creatividad en la generación de ideas para dar respuestas relevantes a los problemas identificados y la equidad en la distribución de los bienes en juego.

Como toda herramienta que involucra la participación directa de los actores, genera desafíos para las estructuras de cogobierno tradicionales y culturalmente arraigadas en las instituciones universitarias, a la vez que contribuye a incrementar el compromiso y la responsabilidad de los actores en los procesos de toma de decisiones, a partir de la inclusión de voces diversas y complementarias, potenciando los resultados de las mismas así como también la legitimidad de las acciones consensuadas en ámbitos de deliberación pública.

El diseño y la implementación del PP estuvieron coordinados desde la Secretaría de Planificación y Gestión Institucional, y se contó con el apoyo de un Comité Asesor integrado por docentes-investigadores de la casa que cuentan con una importante experiencia tanto en la gestión como en el estudio de políticas participativas. También se vieron involucradas activamente las distintas Secretarías y especialmente la Secretaría de Comunicación y Gestión de Medios, a través de la 
cual se difundieron las convocatorias para participar de las actividades, así como también los resultados de cada una de las etapas.

La elaboración del diagnóstico y la formulación, presentación y selección de proyectos fue promovida por los tres claustros, a través de diversos dispositivos, inspirados en experiencias desarrolladas por gobiernos locales que fueron adaptadas para que resultaran efectivas en el contexto institucional de nuestra Facultad.

En los tres talleres de diagnóstico, uno por cada claustro, se trazaron los lineamientos que orientaron la elaboración de los proyectos. En ellos participaron alrededor de ochenta personas. Dentro de las prioridades establecidas en el diagnóstico, el espacio físico y el equipamiento apareció como un aspecto central, lo cual se vio reflejado en todo el proceso.

En la etapa de elaboración de proyectos, se realizaron dos talleres que contaron con la participación de cincuenta personas. Como resultado de los mismos se presentaron cerca de veinte ideas proyecto que finalmente se materializaron en quince proyectos realizados por treinta y cinco proyectistas. Los autores de las ideas proyectos trabajaron en reuniones de diseño con las Secretarías vinculadas con cada propuesta. Por el claustro docente se presentaron ocho proyectos, cuatro por el claustro estudiantil y tres por el claustro no docente.

La votación se llevó a cabo el 16 de noviembre, resultando ganadores tres proyectos: "Refuncionalización de la sala de profesores", por el claustro docente; "Sala multifuncional para estudiantes", por el claustro estudiantil; y "Espacio multifuncional. Re-encontrando nuestro espacio como parte de la comunidad universitaria", por el claustro no-docente.

A través de las distintas etapas de esta primera edición del PP participaron cerca de quinientas personas. Este número constituye un dato significativo, sobre todo considerando el carácter innovador de la propuesta y los tiempos que lleva la apropiación a nivel institucional de nuevas herramientas participativas. Por otro lado, el proceso abierto por el PP tuvo resultados cualitativos aún más importantes: involucró a actores que habitualmente no intervienen en el proceso de toma de decisiones, contribuyó a la difusión de información relevante sobre el funcionamiento de la Facultad y favoreció el debate sobre el presente y el futuro de nuestra comunidad educativa.

Más información: www.fcpolit.unr.edu.ar.

Contacto:ppfcpolit@gmail.com 